\title{
ELECCIONES EN ESTADOS UNIDOS
}

El martes 6 de noviembre de 1984, el candidato republicano, R. Reagan, obtenía sin problemas su reelección como Presidente de los Estados Unidos, al conseguir 525 votos electorales (59 por 100 de votos populares), frente a los 13 votos electorales (41 por 100 de votos populares) del candidato demócrata, W. Mondale.

Reagan obtuvo la reelección con uno de los resultados más espectaculares de la historia electoral norteamericana, bajo unas cotas de popularidad sólo comparables a las del viejo Presidente Roossevelt. Barrió en el Sur, y llegó incluso a vencer en el Medio Oeste, feudo tradicional del Partido Demócrata.

La campaña del candidato republicano estuvo basada en el lema "Poco Estado y mucha Defensa", y en tres claves fundamentales, que nos dan, asimismo, la llave del éxito: su liderazgo personal, la mejora del nivel de vida durante su anterior mandato y el reverdecer del orgullo nacional (America is back). Reagan supone para la mayoria del pueblo americano la recuperación de la confianza nacional, así como la vuelta a las raices de los Padres Fundadores, desvirtuadas por las dosis de keynesianismo de las Administraciones demócratas. Todo ello conlleva, como se ha puesto ya de manifiesto, un desfasado control moral, un renacer del puritanismo que recuerda los años 50 . En definitiva, Reagan es para muchos el espíritu del "american pride" (orgullo de ser americano), la exacerbación del «maccarthismo».

La derrota de Mondale y de Ferraro, la primera mujer candidata a la Vicepresidencia de los Estados Unidos, no estuvo restringida a las elecciones presidenciales, sino que se hizo palpable también en la nueva Cámara de Representantes y en la renovación de un tercio del Senado, en relación a anteriores elecciones (Cuadro 2). 
CUADRO 1

RESULTADOS DE LAS ELECCIONES PRESIDENCIALES *

\begin{tabular}{|c|c|c|c|c|c|c|c|c|}
\hline \multirow{3}{*}{ ESTADOS } & \multicolumn{4}{|c|}{1980} & \multicolumn{4}{|c|}{1984} \\
\hline & \multicolumn{2}{|c|}{$\begin{array}{c}\text { VOTOS } \\
\text { POPULARES }\end{array}$} & \multicolumn{2}{|c|}{$\begin{array}{c}\text { VOTOS } \\
\text { ELECTORALES }\end{array}$} & \multicolumn{2}{|c|}{$\begin{array}{c}\text { VOTOS } \\
\text { POPULARES }\end{array}$} & \multicolumn{2}{|c|}{$\begin{array}{c}\text { VOTOS } \\
\text { ELECTORALES }\end{array}$} \\
\hline & CARTER & REAGAN & CARTER & REAGAN & REAGAN & MONDALE & REAGAN & MONDALE \\
\hline 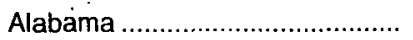 & 626.934 & 640.621 & - & 9 & 851.609 & 545.925 & 9 & - \\
\hline 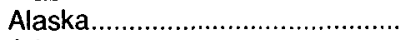 & 31.408 & 66.874 & - & 3 & 115.390 & 51.169 & 3 & - \\
\hline Arizona ...................................... & 243.498 & 523.124 & - & 6 & 676.524 & 330.771 & 7 & - \\
\hline 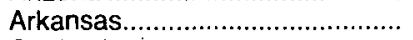 & 397.919 & 409.946 & - & 6 & 529.756 & 336.406 & 6 & - \\
\hline 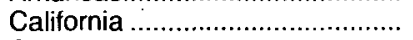 & 3.040 .600 & 4.447.266 & - & 45 & 5.305 .434 & 3.815 .992 & 47 & - \\
\hline 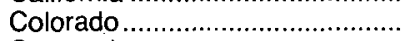 & 368.906 & 650.749 & - & 7 & 768.711 & 434.560 & 8 & - \\
\hline 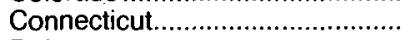 & 537.407 & 672.648 & - & 8 & 883.461 & 561.387 & 8 & - \\
\hline 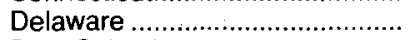 & 106.650 & 111.631 & - & 3 & 151.494 & 100.632 & 3 & - \\
\hline 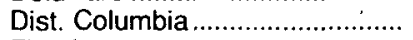 & 124.376 & 21.765 & 3 & - & 26.805 & 172.459 & - & 3 \\
\hline Florida & 1.366 .365 & 1.937 .269 & - & 17 & 2.582 .980 & 1.397 .097 & 21 & - \\
\hline Georgia & 870.483 & 631.470 & 12 & - & 1.060 .680 & 701.605 & 12 & - \\
\hline 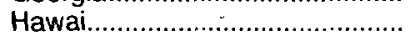 & 135.879 & 130.112 & 4 & - & 185.050 & 146.654 & 4 & - \\
\hline 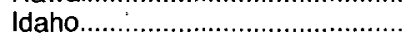 & 109.410 & 290.087 & - & 4 & 296.687 & 108.447 & 4 & - \\
\hline 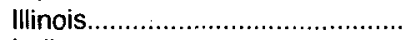 & 1.949 .985 & 2.342 .450 & - & 26 & 2.687 .112 & 2.066 .580 & 24 & 一 \\
\hline 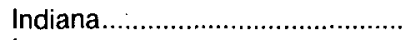 & 835.541 & 1.231 .295 & - & 13 & 1.332 .681 & 814.659 & 12 & - \\
\hline 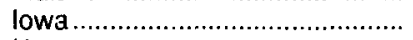 & 508.735 & 676.556 & - & 8 & 700.779 & 603.810 & 8 & 一 \\
\hline 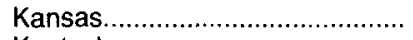 & 324.974 & 562.848 & - & 7 & 675.366 & 332.476 & 7 & - \\
\hline 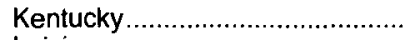 & 609.687 & 625.820 & - & 9 & 816.580 & 535.559 & 9 & - \\
\hline 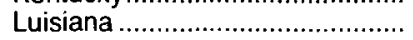 & 707.981 & 796.240 & - & 10 & 1.030 .091 & 648.040 & 10 & - \\
\hline 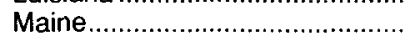 & 220.387 & 238.156 & - & 4 & 336.113 & 212.190 & 4 & - \\
\hline Maryland & 706.327 & 656.255 & 10 & - & 836.395 & 759.205 & 10 & - \\
\hline Massachusetts............................. & 1.048 .391 & 1.054 .390 & - & 14 & 1.297 .737 & 1.226 .490 & 13 & - \\
\hline Michigan ...................................... & 1.519 .474 & 1.808 .832 & - & 21 & 2.247 .058 & 1.528 .558 & 20 & - \\
\hline
\end{tabular}




\begin{tabular}{|c|c|c|c|c|c|c|c|c|}
\hline 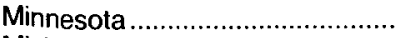 & 897.882 & 824.007 & 10 & - & 1.024 .631 & 1.039 .904 & - & 10 \\
\hline 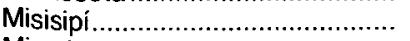 & 428.948 & 439.843 & - & 7 & 585.052 & 351.677 & 7 & - \\
\hline 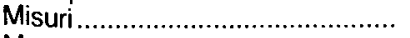 & 917.663 & 1.055 .355 & - & 12 & 1.268 .408 & 838.599 & 11 & - \\
\hline Montana & 109.940 & 191.208 & - & 4 & 214.269 & 135.071 & 4 & 一 \\
\hline 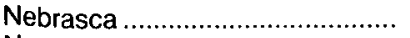 & 164.270 & 413.338 & - & 5 & 447.810 & 184.058 & 5 & 一 \\
\hline 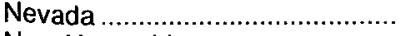 & 66.468 & 154.570 & - & 3 & 188.794 & 91.654 & 4 & - \\
\hline New Hampshire ........................... & 109.080 & 221.771 & - & 4 & 255.140 & 116.284 & 4 & - \\
\hline Nueva Jersey ................................ & 1.119 .576 & 1.506 .437 & - & 17 & 1.914 .942 & 1.255 .115 & 16 & - \\
\hline Nuevo México............................... & 164.794 & 245.191 & - & 4 & 304.323 & 200.703 & 5 & - \\
\hline 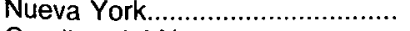 & 2.627 .959 & 2.790 .498 & - & 41 & 3.553 .762 & 3.021 .719 & 36 & - \\
\hline Carolina del Norte ............................. & 875.947 & 916.949 & - & 13 & 1.340 .274 & 821.364 & 13 & - \\
\hline Dakota del Norte ......................... & 71.544 & 175.825 & - & 3 & 199.352 & 103.957 & 3 & - \\
\hline Ohio & 1.744 .266 & 2.202.212 & - & 25 & 2.655 .395 & 1.805 .845 & 23 & - \\
\hline 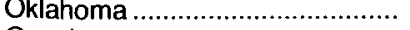 & 390.292 & 683.807 & - & 8 & 861.757 & 384.918 & 8 & - \\
\hline Oregón........................................ & 445.352 & 555.859 & - & 6 & 639.755 & 508.516 & 7 & - \\
\hline Pensilvania .................................... & 1.932.392 & 2.251 .058 & - & 27 & 2.572 .472 & 2.213 .429 & 25 & - \\
\hline Rhode Island .................................. & 185.319 & 145.576 & 4 & 一 & 204.450 & 191.914 & 4 & - \\
\hline 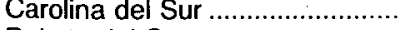 & 422.029 & 445.414 & - & 8 & 561.963 & 316.746 & 8 & - \\
\hline Dakota del Sur ................................ & 103.909 & 198.102 & - & 4 & 198.119 & 114.967 & 3 & - \\
\hline 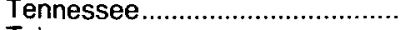 & 781.464 & 787.156 & - & 10 & 1.002 .722 & 705.820 & 11 & - \\
\hline Tejas........................................... & 1.779 .025 & 2.433.290 & 一 & 26 & 3.351 .589 & 1.897 .190 & 29 & - \\
\hline 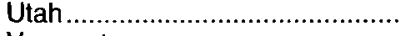 & 123.447 & 435.839 & 一 & 4 & 467.214 & 155.098 & 5 & 一 \\
\hline 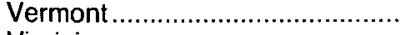 & 81.409 & 93.443 & - & 3 & 134.252 & 94.518 & 3 & 一 \\
\hline Virginia....................................... & 745.600 & 979.871 & - & 12 & 1.338.378 & 798.553 & 12 & 一 \\
\hline 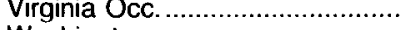 & 353.508 & 326.645 & 6 & - & 945.052 & 736.260 & 10 & - \\
\hline 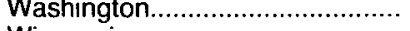 & 583.299 & 763.631 & - & 9 & 400.261 & 324.073 & 6 & - \\
\hline 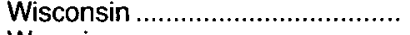 & 988.255 & 1.089 .750 & - & 11 & 1.198 .379 & 992.807 & 11 & - \\
\hline 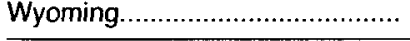 & 49.123 & 110.096 & - & 3 & 132.073 & 53.272 & 3 & 一 \\
\hline TOTAL .......................................... & 34.663 .037 & 42.951 .145 & 49 & 489 & 53.355 .081 & 36.884 .702 & 525 & 13 \\
\hline
\end{tabular}


PILAR MELLADO PRADO

CUADRO 2.

LA VARIACION EN LA CAMARA DE REPRESENTANTES

\begin{tabular}{lccc}
\hline & REPUBLICANOS & DEMOCRATAS & OTROS \\
\hline COMPOSICION ACTUAL & 183 & 252 & - \\
\hline COMPOSICION 1980 & 167 & 266 & (dOs vacantes) \\
\hline VARIACIÓN & +16 & -14 & \\
\hline
\end{tabular}


CUADRO 3. LA NUEVA CAMARA DE REPRESENTANTES *

\begin{tabular}{|c|c|c|}
\hline ESTADOS & REPUBLICANOS & DEMOCRATAS \\
\hline Alabama & 2 & 5 \\
\hline Alaska & 1 & - \\
\hline Arizona & 4 & 1 \\
\hline Arkansas & 1 & 3 \\
\hline California & 18 & 27 \\
\hline Colorado & 4 & 2 \\
\hline Connecticut & 3 & 3 \\
\hline Delaware & - & 1 \\
\hline Florida & 7 & 12 \\
\hline Georgia & 2 & 8 \\
\hline Hawaii & - & 2 \\
\hline Idaho & 1 & 1 \\
\hline Illinois & 9 & 13 \\
\hline Indiana & 6 & 4 \\
\hline lowa & 4 & 2 \\
\hline Kansas & 3 & 2 \\
\hline Kentucki & 3 & 4 \\
\hline Loisiana & 2 & 6 \\
\hline Maine & 2 & - \\
\hline Maryland & 2 & 6 \\
\hline Massachusetts & 1 & 10 \\
\hline Michigan & 7 & 11 \\
\hline Minnesota & 3 & 5 \\
\hline Mississippi & 2 & 3 \\
\hline Missouri & 3 & 6 \\
\hline Montana & 1 & 1 \\
\hline Nebraska & 3 & - \\
\hline Nevada & 1 & 1 \\
\hline New Hampshire & 2 & - \\
\hline New Jersey & 6 & 8 \\
\hline New México & 2 & 1 \\
\hline New York & 15 & 19 \\
\hline Carolina del Norte & 5 & 6 \\
\hline Dakota del Norte & - & 1 \\
\hline Ohio & 10 & 11 \\
\hline Oklahoma & 1 & 5 \\
\hline Oregón & 2 & 3 \\
\hline Pennsylvania & 10 & 13 \\
\hline Rhode Island & 1 & 1 \\
\hline Carolina del Sur & 3 & 3 \\
\hline Dakota del Sur & - & 1 \\
\hline Tennessee & 3 & 6 \\
\hline Texas & 10 & 17 \\
\hline Utah & 3 & - \\
\hline Vermont & 1 & - \\
\hline Virginia & 6 & 4 \\
\hline Washintong & 3 & 5 \\
\hline West Virginia & - & 4 \\
\hline Wisconsin & 4 & 5 \\
\hline Wyoming & 1 & - \\
\hline Total & 183 & 252 \\
\hline
\end{tabular}

Fuente: National Journal de 10 de noviembre de 1984, facilitado por el Centro Washintong Irving de los Estados Unidos en Madrid. 